\title{
La cueva de los Ermitons (Sales de Llierca, Girona): un yacimiento del Paleolítico Medio final *
}

\author{
Julià MAROto GenOVER**
}

\section{ANTECEDENTES}

La cueva de los Ermitons (Sales de Llierca, Garrotxa, Girona) fue excavada por las profesoras A. M. Muñoz y M. L. Pericot entre 1970 y 1971. Los resultados de su excavación y el primer estudio del yacimiento los encontramos en MUÑOz y PERICOT (1975) y PERICOT y FULLOLA (1975), que se publican conjuntamente. En la primera referencia, además, se da un resultado preliminar de la datación absoluta, mientras que en la segunda se interpreta la industria lítica como perteneciente al Musteriense tipo Quina. Así en esta publicación ya se anuncia que el yacimiento pertenece al Paleolítico Medio final.

En 1978 se publica la datación absoluta (ALmagro et al. 1978) que verifica la datación preliminar.

A partir de 1981 tomamos interés por el yacimiento. En una nota previa (MAROTo 1983) anunciamos que el Musteriense no es de tipo Quina y posteriormente publicamos (MAROTO 1986) un resumen del estudio sobre su geología, interpretación funcional, estratigrafía y sedimentología, restos faunisticos e industria lítica. Ahora presentaremos el yacimiento analizado dentro del contexto europeo del paso del Paleolítico Medio al Superior y de la aparición en la Europa occidental del hombre moderno, además de repetir los principales datos estudiados anteriormente.

* Comunicación presentada en el coloquio internacional El origen del hombre moderno en el suroeste de Europa (Madrid, 17-19 de octubre de 1991), organizado por la U.N.E.D. y coordinado por la profesora Victoria Cabrera.

** Centre Associat de la U.N.E.D. Girona. Centre d'Investigacions Arqueològiques. Girona. 
SITUACIÓN GEOGRÁFICA Y GEOLÓGICA E INTERPRETACIÓN ESPACIAL DEL YACIMIENTO

La cueva de los Ermitons se encuentra en el interior del macizo calcáreo de la Alta Garrotxa, en el Prepirineo suroriental (nordeste de Cataluña y de la Península Ibérica), a 400 metros de altitud y a 95 metros por encima del torrente de Sant Aniol (fig. 1).

Partiendo del valle del río Fluvià, el acceso natural al macizo se realiza por el valle del río Llierca.

El clima actual es mediterráneo húmedo, intermedio entre el mediterráneo típico y el de tendencia atlántica. Destacan las precipitaciones abundantes, superiores a los $1.000 \mathrm{~mm} / \mathrm{año}$.

El substrato geológico mayoritario está formado por calizas ecocénicas tremendamente fracturadas y karstificadas. El acceso al yacimiento no es fácil. Su relieve circundante es muy accidentado y abrupto, debido a la litología, dominada por calizas masivas, y a la estructura, que ha originado fuertes plegamientos.

De esta manera, el macizo es poco transitable. Hay acantilados insalvables y las pronunciadas pendientes - como la de la vertiente de la cueva, del $60 \%$ - son muy abundantes.

Los ríos, muy encajados, son las únicas vías de penetración al macizo. Este paisaje topográfico actual sería muy parecido al existente durante la última glaciación. Por tanto, los condicionantes del hábitat humano han sido siempre la pendiente escarpada, la fuerte limitación de la transitabilidad y la mucho mayor facilidad de movimiento a lo largo de los ríos.

Hemos realizado los mapas de territorio de 1 hora y de 3 horas (lugares a los que se puede acceder desde el yacimiento con unos radios de acción de 1 hora y de 3 horas). Con el mapa de territorio de 1 hora no se sale del interior del macizo y por tanto la obtención de recursos a sólo 1 hora de la cueva es muy complicada.

Por todo ello, nuestra interpretación sobre la utilización del yacimiento durante el Paleolítico es la de un lugar de ocupación esporádico con un objetivo, la caza puntual de la cabra montés, muy bien representada entre los restos faunísticos procedentes del relleno de la cueva. Los lugares más favorables para esta caza serían los puntos donde el río estuviera encogido; las cabras pueden bajar a beber al río al atardecer, y utilizan éste durante la circulación estacional. Sería una caza, evidentemente, con pocas garantías de éxito. 

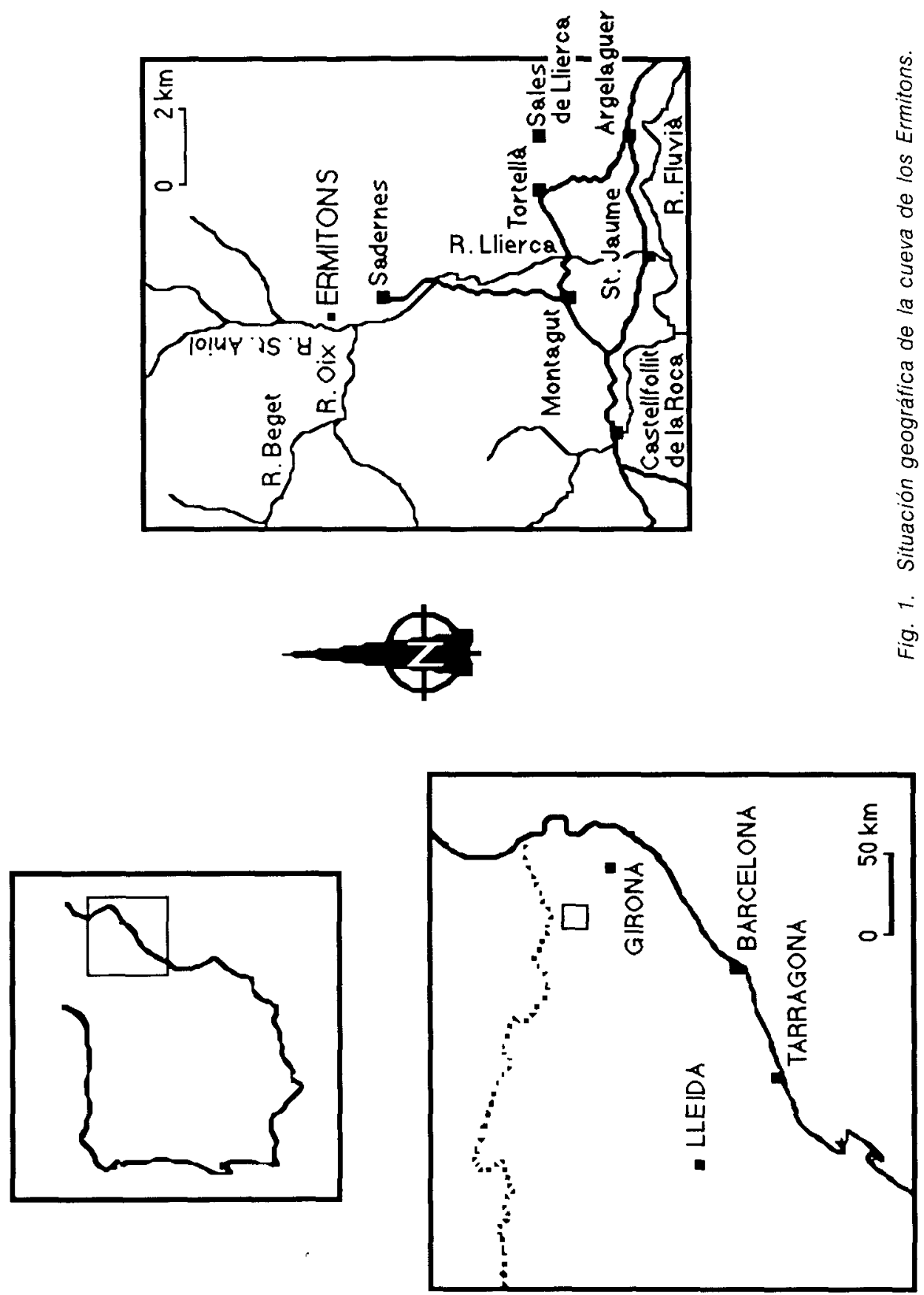


\section{EL YACIMIENTO}

\section{Descripción morfológica}

La cueva constituye actualmente una única galería kárstica, de unos 63 metros de longitud, de recorrido bastante rectilíneo y ascendente (pendiente global actual del $32 \%$ ), de orientación general E-O, pero con el tramo final orientado hacia el sur y suroeste; su extremo interior se encuentra colmatado de arcilla (figs. 2 y 3). Hoy en día la cavidad está inactiva, desconectada de la zona activa del karst que se encuentra, suponemos, a un nivel mucho más inferior.

La entrada, de unos 3,5 metros por 2 metros, es de forma subtriangular; en ella se puede observar la influencia del medio externo, cosa que no ocurre en el interior. Esta entrada ha retrocedido un trecho del orden de los 10 metros como mínimo, hecho que nos indica que el lugar en donde se realizó la excavación arqueológica y que actualmente recibe la luz natural, estaría total o casi totalmente a oscuras cuando fue ocupado por el hombre paleolítico.

Los aportes sedimentarios proceden del interior de la cavidad. La pendiente de la galería ha favorecido la circulación del agua infiltrada en superficies topográficamente más altas y su salida por ella, en cuyo extremo se encuentra el yacimiento. Esta circulación ha producido el transporte y la sedimentación de la mayor parte de los aportes sedimentarios, así como su erosión.

La posible área de infiltración la hemos localizado en el exterior, aguas arriba, en una zona con un lapiaz desarrollado.

Dentro de los aportes sedimentarios encontramos una gran cantidad de cantos rodados, que proceden de la misma cueva. La roca presenta diaclasas en dos direcciones aproximadamente perpendiculares que aíslan fragmentos de caliza. La circulación de agua por las diaclasas favorece la descalcificación en estos puntos y los fragmentos de caliza se van redondeando in situ, de tal manera que cuando caen, lo hacen en forma de canto rodado. De los cantos que actualmente se encuentran en superficie en la galería, la mayoría están rodados.

\section{El depósito}

\section{ESTRATIGRAFIA}

Tenemos documentado un mínimo de tres metros de potencia en el centro de la galería excavada, de los cuales la mitad superior corresponde a sedimentos arqueológicos repartidos en seis estratos. 


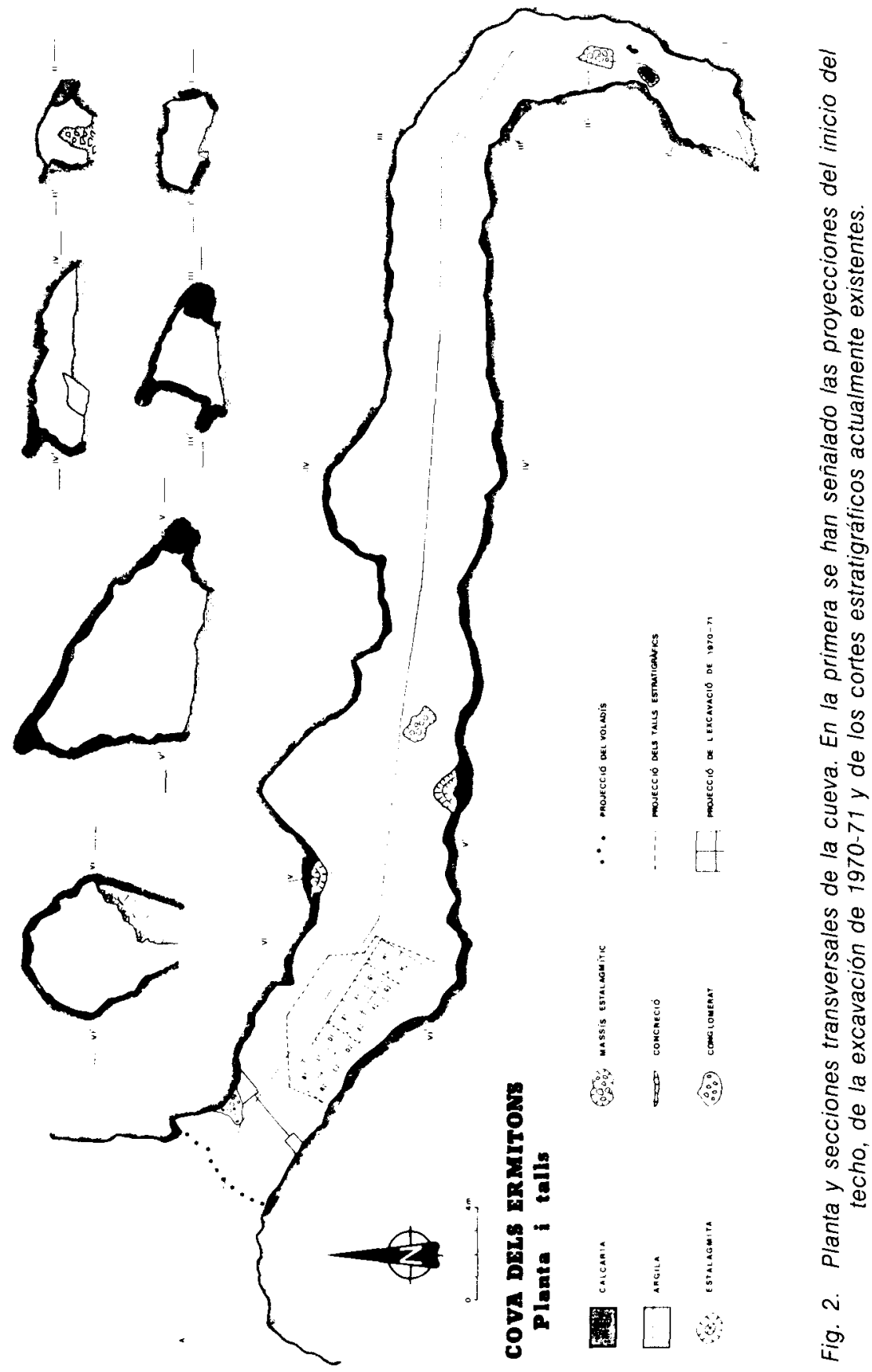




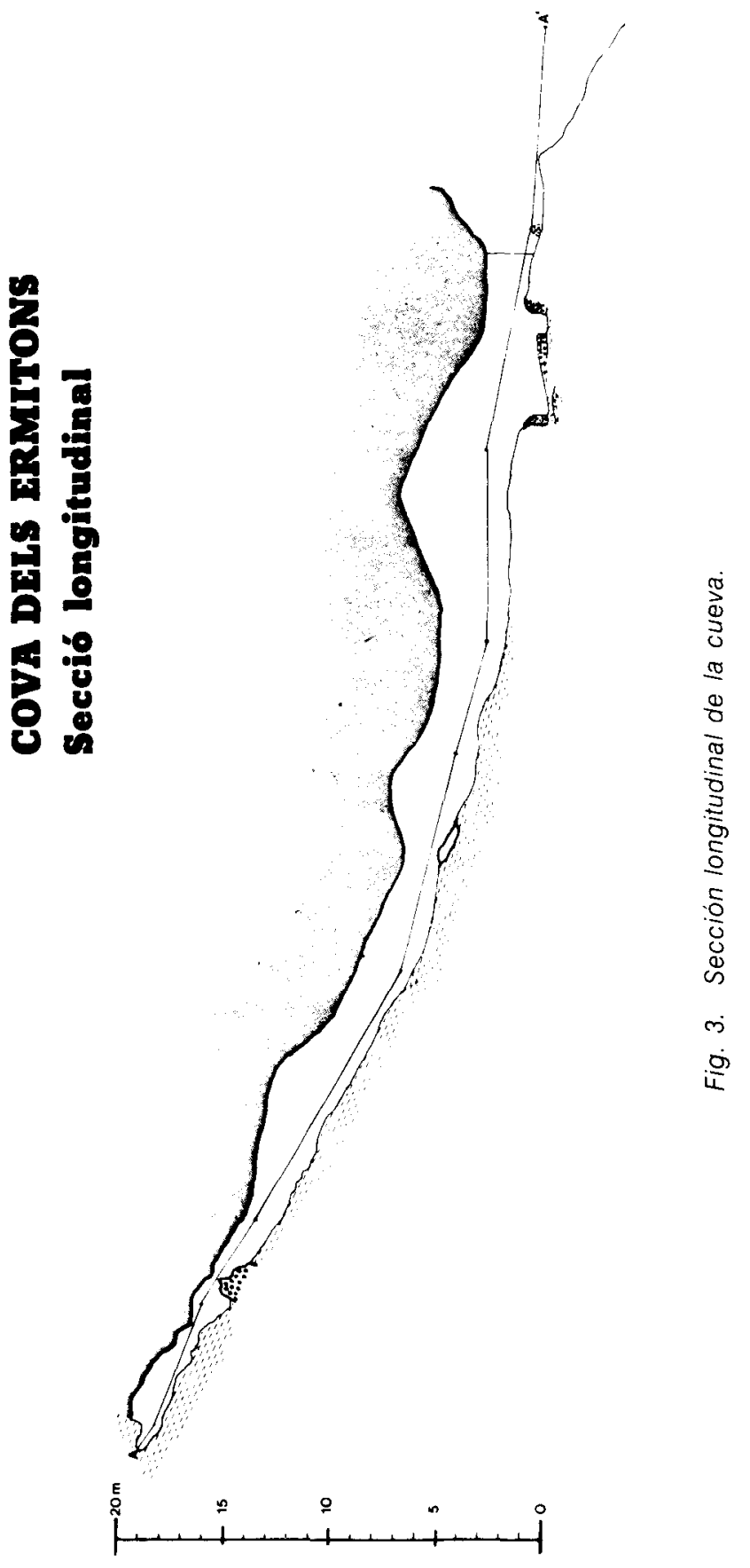


El depósito lo hemos descrito en los cortes de factura irregular (secciones 1 a 6 ), situados en el sector donde tuvo lugar la excavación de 1970-71 y que en parte son los dejados en ella y en parte son el resultado de la acción de los furtivos que en años posteriores visitaron el yacimiento.

Los contactos entre los estratos son siempre, a excepción del caso que se cita, netos y erosivos. De arriba a abajo tenemos los estratos que se describen a continuación (fig. 4).

Estrato I. Compuesto de sedimento no consistente, poco compactado, polvoriento, de tamaño arcilla mayoritariamente, de color ceniza y que contiene numerosos guijarros de caliza, redondeados y angulosos, con predominio de los primeros. No está estructurado y es muy fácilmente erosionable. Su potencia es muy irregular, de $1 \mathrm{~cm}$ a $20 \mathrm{~cm}$.

Estrato II. Gravas de pequeña dimensión, con matriz predominantemente arcillosa amarillenta (en algunos puntos rojiza o grisácea). Los guijarros de caliza, redondeados, comprendidos entre $1 \mathrm{~cm}$ y $3 \mathrm{~cm}$, se presentan en densidades variables, aunque normalmente no se tocan. Su espesor está comprendido entre $5 \mathrm{~cm}$ y $20 \mathrm{~cm}$. Sólo lo encontramos en la zona interna; hacia el exterior desaparece (nos verifica que los sedimentos proceden del interior). El contacto con el estrato inferior a veces es neto y a veces parece transicional.

Estrato III. Gravas de tamaño variable donde los cantos calcáreos, rodados y predominantemente alargados, se tocan todos los unos a los otros y dejan espacio para muy poca matriz, que es esencialmente arcillosa (rojiza o amarillenta). En algún punto están concrecionadas y forman un verdadero conglomerado. En la zona más intersa, secciones 1. ${ }^{a}$ y $2 .^{a}$, muchos de los cantos, quizás la mitad, están ligeramente imbricados y con su diámetro máximo perpendicular al sentido del flujo, cosa que nos indica el sentido de la corriente de dentro hacia afuera, y que el transporte fue tractivo. Después se disponen generalmente planos y comienzan a disminuir de tamaño. Éste varía entre unos $8 \mathrm{~cm}$ y $20 \mathrm{~cm}$, hacia el interior, y $3 \mathrm{~cm}$ y $7 \mathrm{~cm}$ hacia el exterior.

Estrato $\mathrm{N}$. Predominantemente de arcilla rojiza, terra rossa. Contiene en su interior, sin orden o estructura aparente, diversos cantos rodados y algunos angulosos, todos de tamaño variable, así como, ocasionalmente, algunos bloques de caliza o estalagmita. Se observa en todo él la presencia de coprolitos, sobre todo en el sector más externo, donde son muy abundantes. Su potencia aumenta desde $30 \mathrm{~cm}$ hacia el interior hasta $65 \mathrm{~cm}$ hacia el exterior.

Estrato V. Gravas de tamaño variable donde los cantos de caliza, rodados y alargados, se tocan unos con otros (equiparable al estrato III). 

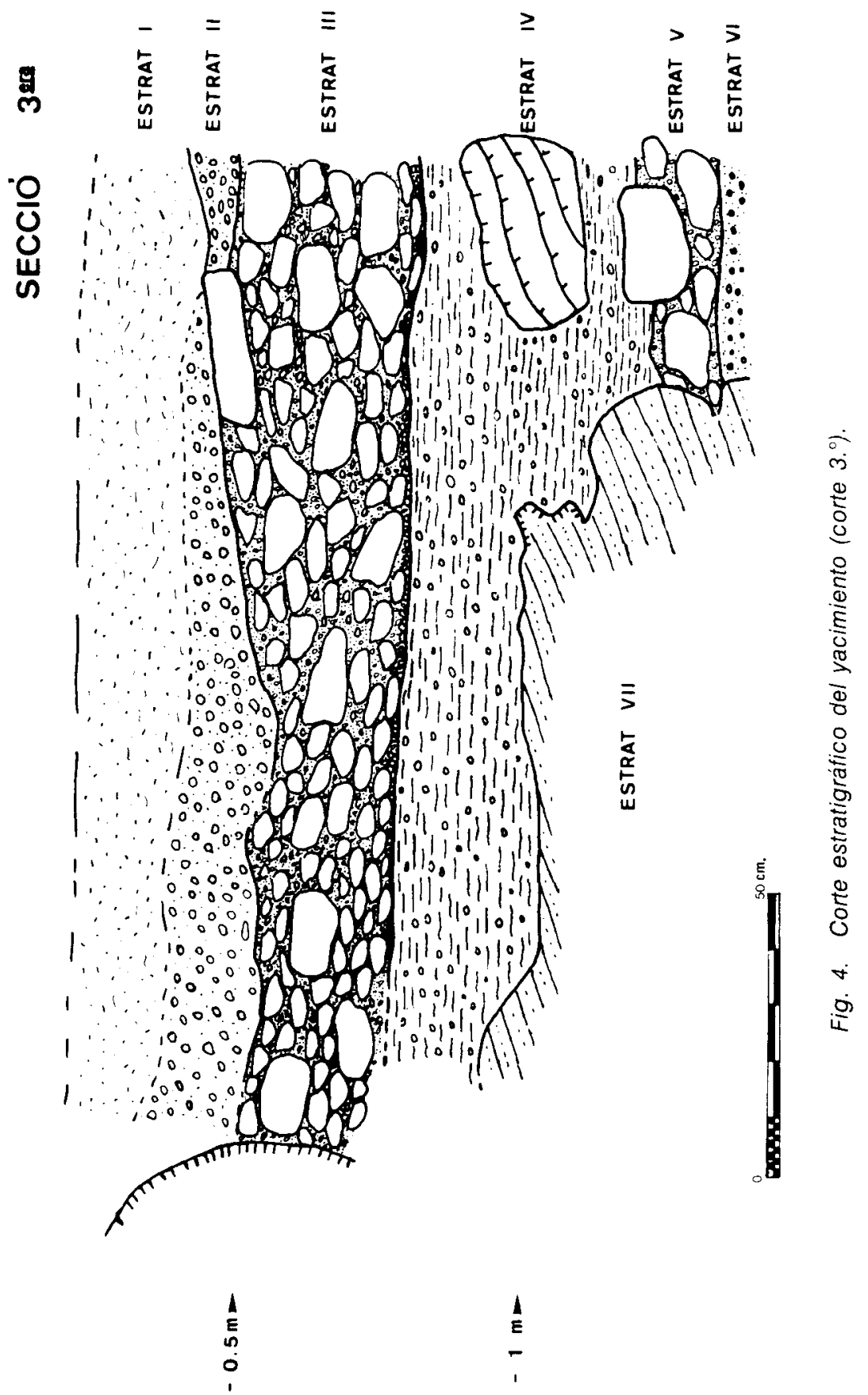
La escasa matriz es arcilla igual a la del estrato anterior. La pendiente de los cantos es variable, pero predominan los planos. Tienen también una disminución de dimensiones parecida a la del estrato III: entre $6 \mathrm{~cm}$ y 12 $\mathrm{cm}$ hacia el interior, y entre 3 y $4 \mathrm{~cm}$ hacia el exterior. Contiene asimismo algún bloque no demasiado grande. La potencia observada varía entre 15 $\mathrm{cm}$ y $25 \mathrm{~cm}$.

Estrato VI. Formado por tres tipos de facies o capas diferentes. La más abundante contiene multitud de pequeños cantos rodados del orden de $1 \mathrm{~cm}$ dispuestos aparentemente sin ningún orden, y también otros, algunos angulosos, de tamaños diferentes, todos acompañados de una matriz arenosa-arcillosa calcificada y amarillenta. Las otras dos son variantes de ésta: una predominantemente caliza, con los pequeños guijarros tocándose, y la segunda, compuesta casi exclusivamente de arena gruesa poco lavada. También encontramos dentro del estrato, localmente, grandes bloques de caliza y estalagmita. Tiene una potencia de unos $40 \mathrm{~cm}$ (sólo lo hemos podido observar bien en la zona más interna).

Grupo de estratos VII. Es un conjunto de estratos arqueológica y paleontológicamente estériles que forman una unidad sedimentaria y que hemos agrupado convencionalmente para facilitar la descripción. Está constituido mayoritariamente por arenas poco lavadas de granulometría variada, con estratificación cruzada planar de gran ángulo. Las láminas, predominantemente tractivas, alternan su granulometría desde tamaño microconglomerático hasta arena fina, pero también hay de limos y arcillas, posiblemente de decantación. Todo el conjunto constituye una barra lateral dentro de la cueva. La presencia de algunos ripples nos confirma el sentido de la paleocorriente de dentro hacia afuera. La potencia mínima es de $230 \mathrm{~cm}$, bien que sólo es indicativa, ya que no sabemos cuánto más puede bajar. La disposición de su techo, muy irregular, determina la posición de los sedimentos que lo cubren, siempre mostrando una discordancia angular.

\section{INTERPRETACIÓN SEDIMENTOLÓGICA}

La barra lateral que constituye los estratos inferiores (VII) fue depositada por un caudal de régimen bastante continuo, al menos estacional. Representa abundantes precipitaciones durante un tiempo muy largo, en el cual la cueva estaría a menudo inundada por agua.

El estrato VI parece reflejar una dinámica de escorrentía superficial de pulsaciones esporádicas. Su techo se encuentra erosionado, quizás por la misma dinámica que deposita después el estrato $\mathrm{V}$. 
El estrato $V$ corresponde también a una dinámica de escorrentía superficial de pulsaciones esporádicas, pero con un poder de arrastre mayor, que parece corresponder a un clima más árido que el actual. Su techo se encuentra erosionado también, seguramente, por la misma dinámica.

Quizás después de un cierto tiempo de interrupción sedimentaria se deposita el estrato IV, que corresponde a una dinámica de escorrentía superficial con poco poder de arrastre y que decantaría la arcilla transportada por suspensión. Interpretamos que este estrato responde, seguramente, a un clima más húmedo que el actual, necesario para producir terra rossa que esté a disposición del agente de transporte, aunque no $\tan$ lluvioso como el del conjunto VII.

Después de otra interrupción sedimentaria, encontramos la deposición del estrato III, la dinámica del cual quizás erosionó el techo del anterior. Para este estrato III proponemos la misma interpretación que hemos hecho para el $\mathrm{V}$.

El estrato II nos refleja pulsaciones menos intensas, que quizás nos marquen, dada su posición estratigráfica, el inicio del descenso de la salida del sistema hidrológico.

El estrato I no es un estrato propiamente dicho; es una acumulación de polvo de procedencia diversa y de algunos cantos de la cueva, producida durante el mucho tiempo en que la cueva ha estado inactiva.

\section{Datación absoluta}

El estrato IV está datado en $36.430 \pm 1.800 \mathrm{BP}$ (CSIC-197) por el método del ${ }^{14} \mathrm{C}$ convencional a partir de una muestra de huesos (ALMAGro et al. 1978; MAROTO 1986). Si bien esta cronología no está corroborada todavía por el método del ${ }^{14} \mathrm{C}$ del acelerador de partículas, y por tanto no nos asegura su pertenencia al final del Paleolítico Medio en sentido estricto, sí nos hace referencia al final del Paleolítico Medio en un sentido amplio y dentro del contexto de otras dataciones similares obtenidas también por el ${ }^{14} \mathrm{C}$ convencional.

\section{LOS MATERIALES}

\section{Correlación con la estratigrafía}

La correlación entre los estratos por nosotros definidos y los materiales arqueológicos procedentes de la excavación de A. M. ${ }^{a}$ Muñoz y M. ${ }^{a} L$. Pericot es la siguiente. 
Estrato I (superficial): mezclado, con materiales que van desde el Bronce Final hasta la actualidad.

Estrato 11: Bronce Final o Neolítico Antiguo.

Estrato III: Neolítico Antiguo.

Estrato IV: Paleolítico Medio.

Estrato V: Paleolítico Medio.

Estrato VI: Paleolítico Medio.

La presencia de materiales correspondientes al Neolítico Antiguo es interpretada por TARRÚs (1982) y BOSCH (1991). Según MUÑOz y PERICOT (1975) estos materiales corresponden al Bronce Final y, por tanto, según esta opinión, a él habría que asignar los estratos II y III.

\section{La fauna paleolítica}

La fauna paleolítica está caracterizada por el predominio absoluto de dos especies: el oso de las cavernas y la cabra montés. En un caso, una será más abundante; en otro caso, lo será la otra.

Los valores que damos para cada estrato no son concretos debido a que la correlación entre la estratigrafía interpretada por MUÑOz y PERICOT (1975) y la que nosotros interpretamos no es matemática, con lo que hay bastante material que no sabemos si pertenece a uno u otro estrato.

Estrato IV. Hay un predominio del oso de las cavernas (Ursus spelaeus), con un N.R. (número de restos) entre el 53 y el $60 \%$ y un N.M.I. (número mínimo de individuos) de seis a ocho, seguido por la cabra (Capra pyrenaica), con un N.R. correspondiente al 35-40\% y un N.M.I. de cinco a seis. De ambas especies hay representados animales jóvenes, adultos y viejos. También podrían estar representados en este estrato, esporádicamente, la hiena (Crocuta spelaea), la pantera (Felis pardus), el lobo (Canis lupus) y el zorro (Vulpes vulpes).

Estrato V. Aquí la proporción de la cabra (31-59\% del N.R. y N.M.I. entre dos y cinco) y del oso (33-52\% del N.R. y N.M.I. de uno a cuatro) es parecida. También podría estar presente el rinoceronte (Dicerorhinus sp.) y el lince (Lynx pardina). Bien que dado el carácter tan tractivo de este estrato, es mejor no utilizarlo como unidad de ocupación.

Estrato VI. La cabra predomina ampliamente $(82 \%$ del N.R. y N.M.I. entre cuatro y ocho) sobre el oso (6-10\% del N.R. y N.M.I. de uno a dos). Encontramos también la pantera, el lobo, el rebeco (Rupicapra rupicapra) y un resto del gran bóvido paleolítico (Bos-Bison). 
Además hay que citar los restos de aves, que han sido clasificados por LI. García. Tenemos un individuo de gavilán (Accipiter nisus) en el estrato IV; un individuo de paloma bravía o paloma zurita (Columba liviaoenas) en el IV y otro en el $\mathrm{V}$; un individuo de chova de pico amarillo (Pyrrhocorax cf. graculus) en el VI.

Esta presencia casi exclusiva de cabras y carnívoros concuerda con el paisaje extremadamemte abrupto que rodea la cueva. Creemos que el oso ocuparía la cueva en épocas en que ésta no estuviera habitada por el hombre. Hemos visto que el estrato IV está lleno de coprolitos de arriba a abajo, cosa que nos puede indicar un hábitat continuado de osos y/o hienas; los mismos carnívoros podían haber dispersado los restos óseos por la cueva. La repartición de huesos de oso es muy representativa de los de todo el cuerpo, en contraste con los de la cabra, donde predominan básicamente los dientes. Igualmente, la presencia de un fragmento de cráneo de neonato en el estrato IV, nos hace pensar en la hipótesis de un lugar de habitación de úrsidos con crías.

Para el estrato VI también pensamos en una alternancia entre el hombre y los carnivoros, bien que ahora la importancia de estos últimos es bastante menor.

Por lo que respecta a la cabra, puede haber sido aportada al yacimiento por el hombre y por los carnivoros. La primera posibilidad viene reforzada por la existencia de señales de acción antrópica sobre algunos huesos de cabra, por la citada desigualdad en la representación del esqueleto y porque su máxima frecuencia coincide con la máxima de la industria lítica y la mínima de los restos de oso. Sin embargo, no hemos de descartar que una parte de estos restos fuera aportada a la cueva por el oso o por los otros carnívoros, sobre todo para el estrato IV; dos huesos de cabra del estrato IV y uno del VI presentan señales de haber sufrido la acción de los carnívoros.

\section{La industria paleolítica}

\section{DESCRIPCIÓN}

La cueva contiene tres estratos paleolíticos con industria musteriense (estratos IV, V, VI), concentrándose ésta principalmente en el inferior (VI).

Debido a la dificultad que tenemos para separar los restos líticos por estratos según nuestra descripción estratigráfica, analizaremos toda la industria paleolítica globalmente. En principio - los materiales no nos lo 
permiten precisar con detalle- no hay diferencias tipológicas y tecnológicas entre ellos.

Esta industria musteriense se presenta bajo un aspecto morfológico y técnico aparentemente particular, al que hay que añadir la existencia de algunos útiles de tipo Paleolítico Superior fig. 5).

En realidad, este aspecto morfológico y técnico particular es efectivamente bastante aparente y se debe a que la industria está muy determinada por la materia prima de origen local, recogida muy cerca de la cueva, de pobre categoría y que determina una mala calidad de talla (débitage, explotación) y de retocado (façonage, configuración). Estas materias son las siguientes: corneana $(21,6 \%)$, cuarzo $(19,8 \%)$, sílex $(18,2 \%)$, arenisca grauvática recristalizada $(9,7 \%)$, cuarcita $(9,1 \%)$, microgranito $(6,3 \%)$, lidita $(5,4 \%)$, arenisca recristalizada $(4,8 \%)$ y otras en menor proporción (granito fino, feldespato, microdiorita, esquisto).

Las lascas Levallios son poco numerosas $(11,9 \%)$, pero aunque algunos núcleos parezcan discoidales y otros poliédricos, en realidad la talla es Levallios.

Presenta una proporción muy elevada de útiles retocados (más del $40 \%$ ), realizados sobre lascas $(74,1 \%)$ y sobre fragmentos de talla $(25,9 \%)$. El retoque mayoritario es el sobreelevado. Los útiles más abundantes son: las raederas $(55,2 \%)$, los denticulados $(19,4 \%)$ y las muescas $(14,0 \%)$.

Merece destacarse igualmente la presencia de algunos pequeños útiles con retoques abruptos delgados y semiabruptos delgados, no reconocidos hasta ahora en los otros yacimientos musterienses de Cataluña, así como de algunos raspadores, buriles y perforadores, y de una punta de Chatelperron.

Hay una industria de aspecto morfológico y técnico general muy parecido a la de los Ermitons: la de la cueva del Mig (Cornellà de Conflent, Roussillon), al otro lado de los Pirineos, a unos 36 kilómetros aproximadamente al nornordeste en línea recta (aunque muchos más en distancia real), atribuida en su momento por su excavador, Y. Blaize, a un Musteriense tardío, que de momento no está datado (BLAIZE 1986, 1987); esta coincidencia es fruto de una misma utilización de materias primas y de soportes.

\section{INTERPRETACIÓN}

De confirmarse la actual datación para la industria de los Ermitons, dentro del contexto de una presencia antigua del Auriñaciense en la cer- 


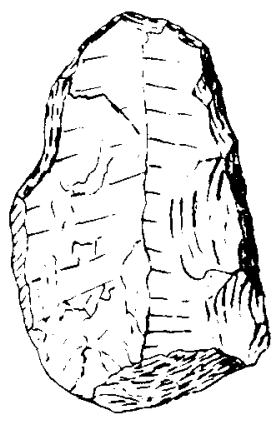

1
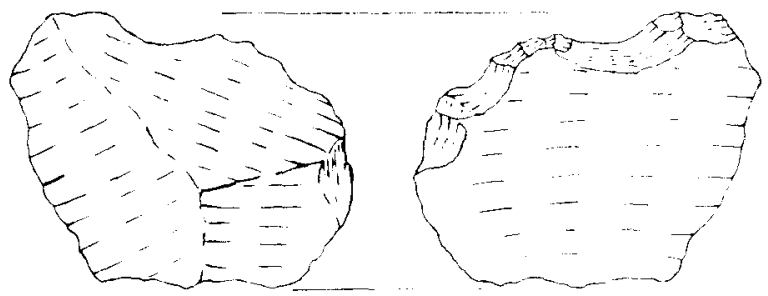

4

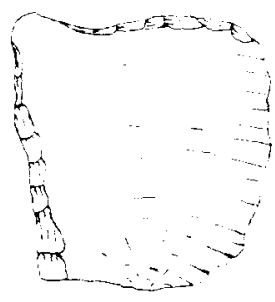

2

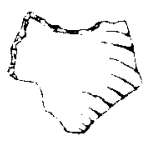

7
$0 \quad 3 \mathrm{~cm}$

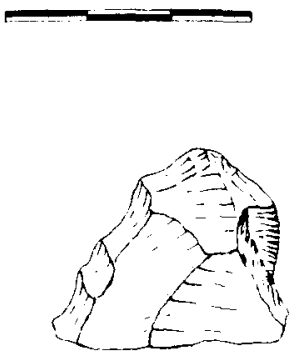

3

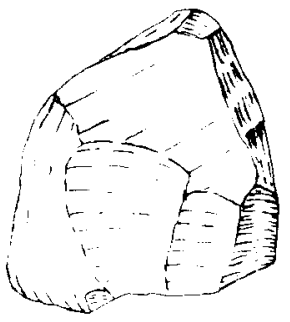

5

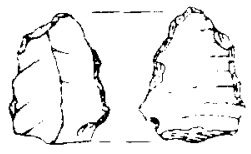

8

Fig. 5. Industria lítica musteriense de la cueva de los Ermitons. 1: raedera lateral derecha, con retoque escamoso-escaleriforme, de lidita; 2: raedera doble inversa, 3: denticulado, de corneana; 4: denticulado inverso, sobre lasca Levallois; 5: núcleo, de corneana; 6: raspador, de silex; 7: abrupto (dorso y truncadura) inverso, de silex; 8: truncadura directa, raedera marginal alterna y denticulado marginal inverso, de sílex. 
cana cueva de l'Arbreda (Serinyà), datado en $38.500 \pm 1.000$ por ${ }^{14} \mathrm{C}$ con el método del acelerador de partículas (BisChOFf et al. 1989; MAROTO y SOLER 1990; SOLER y MAROTO 1990), quizás la presencia de los útiles con retoques abruptos delgados y semiabruptos delgados, entre otros, podría representar un indicio de aculturación -acculturation, en el sentido aplicado por Demars y HUBLIN (1990) - en este Musteriense, que por otra parte tiene la misma talla Levallois presente en otros yacimientos musterienses de Cataluña, como los del área próxima de Serinyà, situada a unas cinco horas y media de camino a pie.

Esta hipótesis está, consecuentemente, por verificar. Además, no podemos esconder la existencia de un argumento adverso a ella, que es la no concentración aparente en el estrato IV de los útiles que supuestamente nos indican la aculturación. La interpretación sedimentológica nos hace intuir una edad diferente para el estrato $\mathrm{VI}$ a la del IV, y por tanto hay la posibilidad que este estrato VI sea anterior a la llegada del Auriñaciense. Una datación absoluta del mismo nos ayudaría mucho a solventar el problema, que en todo caso necesitará de una nueva excavación del yacimiento para su resolución definitiva.

\section{CONCLUSIÓN}

Así, a la espera de nuevos datos, interpretamos provisionalmente el yacimiento paleolítico de la cueva de los Ermitons como un hábitat esporádico utilizado para la caza de la cabra montés (Capra pyrenaica) por parte de los últimos hombres de Neandertal, talladores de industria musteriense que aplican la técnica Levallois a partir de materias primas $10-$ cales, que cohabitan con los primeros hombres modernos portadores de la industria auriñaciense, y que presentan unos leves indicios de aculturación debidos a éstos.

\section{ADDENDA}

A punto de enviar este artículo para su publicación, hemos recibido una datación absoluta para el estrato IV de los Ermitons, realizada por el método del ${ }^{14} \mathrm{C}$ con acelerador de partículas, en el Laboratorio de Oxford, para una muestra de hueso y con el siguiente resultado: $33.190 \pm 660$ BP (OxA-3725). Esta datación, que a nuestro entender tiene aún mayor validez que la hasta ahora existente, no solamente por el método empleado, sino también por referirse a una muestra pequeña cogida directamente de las secciones estratigráficas visibles, nos permite mantener 
plenamente la hipótesis que aquí presentamos. Un intento de datación con el mismo método del estrato $\mathrm{VI}$ no ha dado, desgraciadamente, resultado positivo.

\section{RESUMÉ}

La grotte des Ermitons se trouve dans un massif calcaire très abrupte. Son remplissage a trois couches moustériennes, dont la plus récente appartient vraisemblablement au Paléolithique moyen récent. Elles contiennent une industrie moustérienne taillée par le débitage Levallois, mais ce Moustérien présente une qualité mauvaise du débitage et du façonage due à la mauvaise qualité des martières locales. La présence de quelques outils lithiques particuliers pourrait indiquer, peut-être, une légère acculturation des derniers hommes de Néandertal par l'arrivé de l'Aurignacien.

\section{BIBLIOGRAFIA}

Almagro. M.; Bernaldo de Quirós, F.; Fernández-Miranda, M., y López, P. (eds.) (1978): Catálogo de yacimientos arqueológicos con datación mediante carbono-14 de la Península Ibérica e Islas Baleares y Canarias, Instituto Español de Prehistoria del C.S.I.C. y Departamento de Prehistoria de la Universidad Complutense. Madrid, 28 págs.

BISCHOFF, J. L.; SOLER, N.; MAROTO, J., y JULIAA, R. (1989): "Abrupt Mousterian/Aurignacian Boundary at c. $40 \mathrm{ka} \mathrm{bp}$ : Accelerator ${ }^{14} \mathrm{C}$ dates from L'Arbreda Cave (Catalunya, Spain)», Journal of Archaeological Science, n. ${ }^{\circ} 16$. London, págs. 563-576.

BlAIZE, Y. (1986): "Le gisement moustérien de la grotte du Mitg à Corneilla-de-Conflent (Pyrénées-Orientales)", Cahiers Ligures de Préhistoire et de Protohistoire, n. ${ }^{\circ}$, págs. 121 139.

- (1987) : “El jaciment mosterià de la cova del Mig (Cornellà de Conflent, el Rosselló)», Cypsela, VI. Girona. págs. $37-41$

Bosch, A. (1991): El neolitic antic al N.E. de Catalunya, Tesi Doctoral, Universitat Autònoma de Barcelona, 714 págs.

Demars, P. Y. y HUBLIN, J. J. (1989): “La transition néandertaliens/hommes de type moderne en Europe occidentale: aspects paléontologiques et culturels", en VANDERMEERSCH, B. y OTTE, M. (eds.): L'Homme de Néandertal, vol. 7, L'Extinction, ERAUL, n. ${ }^{\circ} 34$. Liége, págs. $23-37$

HubliN, J. J. (1990): "Les peuplements paléolithiques de l'Europe: un point de vue paléobiogéographique", en FARIZY, C. (ed.): Paléolithique moyen récent et Paléolithique supérieur ancien en Europe. Ruptures et transitions: examen critique des documents archéologiques, Mémoires du Musée de Préhistoire d'lle de France, n. ${ }^{\circ}$, Actes du Colloque international de Nemours, 9-10-11 Mai 1988, A.P.R.A.I.F. Nemours, págs. 29-37.

Maroto, J. (1983): "Estat actual de les recerques sobre la cova dels Ermitons", Annals de I'Institut d'Estudis Gironins, n. ${ }^{\circ}$ XXVI. Girona, págs. 3-22.

- (1986): “Un jaciment prehistòric a l'interior del massís de l'Alta Garrotxa: la cova dels Ermitons", Vitrina, n. ${ }^{\circ}$ 1. Olot, págs. 37-48

Maroto, J., y Soleh, N. (1990): "La rupture entre le Paléolithique moyen et le Paléolithique supérieur en Catalogne”, en FARIZY, C. (ed.): Paléolithique moyen récent et Paléolithique supérieur ancien en Europe. Ruptures et transitions: examen critique des documents archéologiques, Mémoires du Musée de Préhistoire d'lle de France, n. ${ }^{\circ} 3$. Actes du Colloque international de Nemours, 9-10-11 Mai 1988, A.P.R.A.I.F. Nemours, págs. 263-265. 
Muñoz, A. M. y Pericot, M. L. (1975): "Excavaciones de la cueva de "Els Ermitons" (Sadernas, Gerona)", Pyrenae, n. ${ }^{\circ} 11$. Barcelona, págs. 7-27.

Pericot, M. L. y Fullola, J. M. (1975): "Análisis de la industria lítica de "Els Ermitons"», Pyrenae, n. ${ }^{\circ} 11$. Barcelona, págs. 27-42.

Soler, N. y MAroto, J. (1990): “El final del Paleolític Mitjà i l'inici del Paleolític Superior a la cova de l'Arbreda (Serinyà)", Cypsela, n. ${ }^{\circ}$ VIII. Girona, págs. 7-13.

TARRús, J. (1982): “El Neolítico Antiguo en el Nordeste de Cataluña y algunas consideraciones sobre los grupos epicardiales catalanes», Le Néolithique ancien Méditérranéen, Actes du Colloque International de Préhistoire. Montpellier 1981, Archéologie en Languedoc, págs. 143-156. 